\title{
SKLADENJSKE KONSTRUKCIJE MED PODREDJEM IN PRIREDJEM
}

\section{Mojca SMOLEJ}

Filozofska fakulteta Univerze v Ljubljani

Smolej, M. (2018): Skladenjske konstrukcije med podredjem in priredjem. Slovenščina 2.o, 6 (2): 186-205.

DOI: http://dx.doi.org/10.4312/slo2.0.2018.2.186-205.

V prispevku se najprej osredotočamo na različne tipe odvisniških stavkov in jih razdelimo v štiri osnovne skupine: $\mathrm{v}$ skupino odvisnikov, ki so del matičnega stavka, skupino odvisnikov, ki niso del jedrne propozicije matičnega stavka, skupino odvisnikov, ki so izhodiščno nestavčnočlenski, in skupino členkovnih odvisnikov. V nadaljevanju podrobno analiziramo zadnji dve skupini, saj sta bili do sedaj v slovenskem jezikoslovju skoraj popolnoma prezrti. Izhajajoč iz analize, predstavimo tudi možne nadaljnje teoretične obravnave odvisnikov.

Ključne besede: odvisniki, psevdohipotaksa, protivni odvisniki, členkovni odvisniki

\section{UVOD}

Stavki v obliki odvisnikov opravljajo številne skladenjske in pomenske vloge. Prav na osnovi njihovih primarnih skladenjskih in pomenskih oz. modifikacijskih vlog lahko zapišemo, da je množica različnih oblik in vlog odvisnikov široka, žal pa še ne popolnoma popisana. Nekateri odvisniki so tako znotraj slovenističnega jezikoslovja skoraj popolnoma prezrti. Dotaknili se bomo vzrokov za pomanjkljivo obravnavo odvisnikov, nato pa skušali podati pregled najpogosteje rabljenih oblik odvisnikov in njihovih skladenjskopomenskih vlog. Opozorili bomo tudi na nujnost vključitve skladenjskega večfunkcijskega razumevanja vezniških sredstev, ki ne sme biti prekrivno $\mathrm{s}$ pomensko ravnino.

Uvodoma bomo na kratko pregledali jezikoslovna dela, ki so med prvimi 
opozarjala na omenjeno problematiko.

\subsection{Priredja, izražena s podrednimi sredstvi}

Leta 1968 je J. Toporišič v članku z naslovom Priredni odnosi $v$ slovenskem knjižnem jeziku zapisal:

Čas, ki nam je bil na razpolago za raziskavo, ne dopušča podrobneje govoriti o priredjih, izraženih s podrednimi sredstvi. /.../ Zdi se nam, da je vsa priredna razmerja mogoče izraziti tudi s podrednimi sredstvi. Vendar bo treba vprašanje, ali imamo v teh primerih še opravka s priredji, in ne že s podredji, rešiti ob kaki drugi priliki /.../ (po Toporišič 1982: 142).

Tovrstne problematike, izražanje priredja s podrednimi sredstvi, so se dotaknili še A. Sovre, J. Gelb in B. Pogorelec. Prvi je v članku Nepravi relativniki (1965) opisal primere, ko se oziralni odvisniki rabijo v vlogi prirednih členov. A. Sovre nepravi relativnik imenuje sintaktični omnibus. ${ }^{1}$

Če da zveza tisti, ki zadovoljiv smisel, je podredje zdravo, če ne, potem nekaj ni v redu. Primer: Za njima je prihitel miličnik, ki ju je vprašal, kaj nosita v aktovkah. /.../ Stavek ki ju je vprašal je torej le po slovnici odvisen od odnosnice miličnik, po svojem bistvu in notranji moči pa ne, zato je ponarejen, nepravi in napačen (Sovre 1965: 125).

Psevdohipotakso je J. Gelb obravnavala v članku Podredje v vlogi priredja. V njem popiše različne primere prirednih skladenjskih razmerij, ki so izražena $s$ podrednimi vezniki.

Protivno razmerje se da izraziti z naslednjimi podrednimi vezniki: namesto da, medtem ko, čeprav, dasi, ko, če, da. /.../ Zanimiv je naslednji primer iz Finžgarja, ko se dekleti pogovarjata o svojem potencialnem možu: Jaz pa tebi rečem: Če ga je meni umoril Herod, ga bo tebi ustrelil cesar = Jaz pa tebi rečem: Meni ga je ustrelil Herod, tebi pa ga bo ustrelil /.../ (Gelb 1969: 137-138).

Na mejne strukture je B. Pogorelec (1963) opozarjala v svoji disertaciji Veznik

1»/O/mnibus zato, ker se relativnemu odvisniku rada po nemarnem oveša funkcija do malega vseh stavčnih zvez, prirednih nič manj nego podrednih.« (Sovre 1965: 125). 
$v$ slovenščini. Pri obravnavi veznikov $d a$, če, $k o, k a r$ se je osredotočala na tiste zveze, ki so po strukturi podredne, po pomenu pa priredne.

Kot druga relativna vezna sredstva uvaja tudi kar stavke, ki po svojem pomenu niso relativni odvisniki. Največkrat to po pomenu sploh niso podredni stavki; v formalnem pogledu stavke sicer uvajajo relativna vezna sredstva, po pomenu pa so to različne priredne ali nerelativne podredne zveze. S prirednimi konstrukcijami (sindetičnimi ali asindetičnimi) lahko zamenjamo kar stavke v naslednjih primerih: /.../ Vera se je sklonila nad mizico, kar je zdaj prvič storila /.../ (Pogorelec 1963: $155)$.

Vsem štirim jezikoslovcem je skupno, da so pri analizi izhajali iz dihotomije skladenjskega razmerja in leksikalnimi oz. vezniškimi sredstvi, ki naj bi pripadali le eni izmed dveh skupin vezniških sredstev: priredni ali podredni. Skladenjsko in pomensko razmerje sta pri vseh močno prepleteni in drugo drugo pogojujeta, zato je pri vseh zaznati zadrego slovnične opredelitve nekaterih vezniških sredstev, ki so, kot je zapisala B. Pogorelec, po strukturi podredni, po pomenu pa priredni.

V nadaljevanju se bomo najprej osredotočili na osnovno razumevanje vloge odvisnikov in vrste odvisnikov ter izhajajoč iz podanih spoznanj, skušali podati možen pogled, možno rešitev prikazane »zadrege« navidezne neusklajenosti površinske in globinske, pomenske ravnine.

\section{OSNOVNE SKUPINE ODVISNIKOV}

Odvisniki se glede na svoje primarne funkcije in pomene med seboj razlikujejo. Razdelili bi jih lahko v štiri osnovne skupine: ${ }^{2}$ a) odvisniki, ki so del matičnega stavka (gre za neke vrste propozicijo v propoziciji), 3 b) odvisniki, ki niso del jedrne propozicije matičnega stavka (gre za družljivost), so pa izhodiščno (neobvezno) stavčnočlenski, c) odvisniki, ki so podredni le na strukturni ravni

\footnotetext{
${ }_{2}$ O prvih dveh skupinah je pisala tudi A. Žele (2016a).

$3 \mathrm{O}$ prilastkovem odvisniku kot propoziciji v propoziciji matičnega stavka je pisal tudi R. Cazinkić (2000/01 in 2004).
} 
in so izhodiščno nestavčnočlenski (če izhajamo iz razumevanja strukturalistične slovnice) in č) odvisniki, ki imajo stavčno strukturo in so podredni le na strukturni ravni, na pomenski oz. modifikacijski ravni pa opravljajo vlogo modifikatorjev matičnega stavka in so po funkciji blizu členkom, zato jih imenujemo členkovni stavki.

Primeri4 posameznih skupin odvisnikov:

a) Odvisniki kot del matičnega stavka

- $\quad$ Kdor ne bo plačeval, ne bo mogel pridelovati hrane.

- Mislim, da v mojem primeru naziv in poklic nimata posebnih korelacij.

- Jasno je, da jim preveč godi posedanje ob oblastnem koritu.

- $\quad$ Ljudje, ki se radi gibljejo, živijo bolj zdravo.5

- Grem, kamor hočem.

Navedeni primeri se med seboj semantično in skladenjsko razlikujejo (prvi je osebkov odvisnik, drugi predmetni, tretji povedkovodoločilni, četrti prilastkov, ${ }^{6}$ peti pa prislovnodoločilni odvisnik), vendar pa jim je skupno to, da so na strukturni in pomenski ravni obvezni. Vsi opravljajo vlogo obveznega stavčnega člena. Vzporedno z vezljivostno kategorijo lahko zapišemo, da je med matičnim stavkom in navedenimi odvisniki izražena vezljivostna moč, kar nadalje pomeni, da vsi odvisniki opravljajo vlogo obveznih določil in so kot taki del matičnega stavka. Odvisnik kot celota predstavlja element propozicije matičnega stavka, zato lahko upravičeno govorimo o propoziciji znotraj

4 Vsi primeri so vzeti iz korpusa Gigafida, http://www.gigafida.net/ (22. 12. 2017).

5 V skupini odvisnikov, ki so del matičnega stavka, so odvisniki dveh vrst. V bodoče bi jih bilo smiselneje obravnavati v dveh ločenih skupinah. Prvo vrsto predstavljajo osebkov odvisnik, predmetni odvisnik in prislovnodoločilni odvisniki kraja in časa. A. Žele (2016a: 302) jih je poimenovala kot prvostopenjske odvisnike. V drugo skupino sodijo razvijajoči odvisniki (A. Zele 2016a: 3012), kot so npr. prilastkovi odvisniki in povedkovoprilastkovi odvisniki. Za obe vrsti odvisnikov je značilna propozicija v propoziciji oz. medpropozicijska vezljivost, zaradi česar so bili vsi navedeni primeri uvrščeni v isto kategorijo oz. skupino.

${ }^{6}$ Gl. tudi S. Kordić (1995). 
propozicije. Tudi odvisnik ima namreč primarno svojo lastno propozicijsko zgradbo. Ker prva skupina ne predstavlja posebnih težav, še posebej ne na ravni slovnične sistematizacije (slovničnega opisa), nadalje pa tudi ne na ravni šolskega oz. didaktičnega prenosa, se bomo raje osredotočili na zadnji dve skupini. Predhodno pa se bomo na kratko ustavili še pri skupini odvisnikov, ki so izhodiščno neobvezno stavčnočlenski.

b) Odvisniki, ki niso del jedrne propozicije matičnega stavka7

- Čeprav je dodatni kisik pri višinski bolezni koristen, je edino pravo zdravilo hiter sestop. ${ }^{8}$

- $\quad$ Ko dobim priložnost, se moram nenehno dokazovati.

- Ker je kalifornijski standard sprejelo še dvanajst drugih zveznih držav, se kmalu obetajo nove tožbe.

- Če bomo perilo sušili v sušilnem stroju, mora biti v pralnem stroju ožeto z najmanj 800 vrtljaji na minuto.

Navedeni primeri se od predhodne skupine ločijo po tem, da na ravni strukture oz. glede na matični stavek niso obvezni. Vzporedno z vezljivostno kategorijo jih lahko opredelimo kot družljive, kar pomeni, da propozicija odvisnika ni vključena v propozicijo matičnega stavka, sta pa obe propoziciji povezani na ravni modifikacije pomenske podstave matičnega stavka. Navedeni odvisniki (prvi je dopustni, drugi časovni, tretji vzročni, četrti pa pogojni) opravljajo vlogo neobveznih stavčnih členov, kar pomeni, da za samo strukturo matičnega stavka niso nujni, so pa obvezni na ravni smisla oz. na ravni ilokucije in posledično perlokucije. Obe propoziciji, tako matičnega stavka kot odvisnika,

\footnotetext{
7 Izraz jedrna propozicija je uporabljen zaradi razlikovanja med propozicijo matičnega stavka in propozicijo odvisnika, ki je hkrati tudi del propozicije matičnega stavka. Matični stavek tako zaobjema lastno, jedrno propozicijo, katere del je tudi propozicija obveznega stavčnočlenskega odvisnega stavka.

${ }^{8}$ Vsi primeri so vzeti iz korpusa Gigafida.
} 
stojita ena poleg druge, soobstajata in sta, kot je bilo že omenjeno, družljivi.

c) Izhodiščno nestavčnočlenski odvisniki

- Medtem ko prvo drži, pa zadnja navedba zahteva zgodovinsko pojasnilo. 9

- Vozim se v napačno smer, proti vzhodu, namesto da bi dirkal proti zahodu, proti Čilu.

- To je obstajalo vseskozi, samo da je bilo zaradi ukvarjanja z drugimi temami manj opazno.

- Če si ti brezposeln, sem jaz super nadobremenjen!

V nasprotju s predhodno skupino, kjer so navedeni odvisniki, ki jih večina slovnic (npr. Slovenska slovnica 1956, Slovenska slovnica 2000), osnovnošolskih in srednješolskih učbenikov za slovenski jezik obravnava in po vsej verjetnosti zaradi enostavnejšega razumevanja predstavlja kar skupaj z obveznimi stavčnočlenskimi odvisniki, je tretja skupina zapostavljena, saj na skladenjskofunkcijski in pomenski ravni izstopa in se vede samosvoje. Kot je bilo navedeno že v uvodu, se je na tovrstne odvisnike opozarjalo ${ }^{10}$ zelo redko. Njihova posebnost je v tem, da so po strukturi vsi podredni, po pomenu pa ne sodijo v nobeno izmed kategorij, ki jih npr. predvideva Slovenska slovnica (2000: 432-436). Prav vse navedene odvisnike lahko namreč pretvorimo v protivna priredna razmerja, s čimer je delno pojasnjena njihova posebnost. $\mathrm{V}$

\footnotetext{
9 Pri izboru primerov, ki so vsi vzeti iz korpusa Gigafida, sta upoštevani diplomski nalogi: D. Gabrovšek (2016) in M. Kos (2016).

${ }_{10}$ Npr. M. Smolej 2011: 78; 2015: 127-137.

Na tovrstno problematiko je opozarjal tudi K. Ahačič (2017: 122):

»Pri določanju odvisnikov in priredij se ne smemo nikoli zanesti samo na značilni veznik, ampak moramo vedno upoštevati tudi pomen in možnost rabe $\mathrm{v}$ prenesenem pomenu. Poglejmo si težak primer iz sodobnega jezika: Med odbojkarskimi legionarji smo s pomočjo Odbojkarske zveze Slovenije v letu 1993 našli le brata Urnaut, medtem ko je spisek za 2005 kar obsežen. Tu veznik medtem ko ne izraža časovnosti: po njem se vsebinsko ne moremo vprašati kdaj? Ipd., pomen pa ne ustreza nobenemu od odvisnikov, ki smo jih spoznali. Pomensko razmerje med odvisnikom in glavnim stavkom je namreč enako kot pri protivnem priredju z veznikom pa.«
} 
priredno izražena razmerja lahko pretvorimo tudi primere druge skupine: npr. Dodatni kisik pri višinski bolezni je koristen, vendar je edino pravo zdravilo hiter sestop; Kalifornijski standard je sprejelo še dvanajst drugih zveznih držav, zato se kmalu obetajo nove tožbe itd., vendar nobena izmed navedenih zvez ni tudi izhodiščno protivna oz. sklepalna, vse namreč pravo protivnost (ali sklepalnost, vezalnost, pojasnjevalnost) zadobijo šele po pretvorbi. Odvisniki tretje skupine so protivni že izhodiščno. Natančneje se bomo na pričujočo skupino osredotočili v naslednjem poglavju.

\section{č) Členkovni odvisniki}

- $\quad$ Ne maram zanj, da boš vedel.

- Če ti rečem, da ne smem!

- Nihče v tem filmu ne pije, kadi ali preklinja, kaj šele, da bi užival kake substance.

Osnovna značilnost odvisnih stavkov zadnje skupine je ta, da je njihova vloga izražanje modifikacije in da kot taki niso vključeni v propozicijo matičnega stavka, kar jih povezuje z drugo in tretjo skupino odvisnikov. Od predhodnih dveh skupin pa se ločijo po tem, da je v okviru modifikacije njihova primarna vloga krepitev ali slabitev gotovostne naklonskosti, zato jih lahko imenujemo tudi členkovni stavki. Izhodiščno so nestavčnočlenski, na ravni skladenjskega razmerja med matičnim stavkom in členkovnim stavkom pa lahko govorimo o psevdohipotaksi.

\section{PROTIVNI ODVISNIKI}

Osredotočili se bomo na odvisnike tretje skupine oz. na odvisnike, ki so že izhodiščno po tradicionalni slovnici obravnavani kot nestavčnočlenski. Po funkciji so zelo blizu neobvezno stavčnočlenskim odvisnikom. S propozicijo matičnega stavka so povezani na ravni modifikacije, zato propozicija odvisnega stavka ni del propozicije matičnega stavka, sta pa obe propoziciji na sporočilni oz. smiselni ali ilokucijski ravni zagotovo neločljivo povezani in se dopolnjujeta. 
Druži jih tudi podredno-priredna pretvorba, le da neobvezno stavčnočlenski odvisniki primarno izražajo eno izmed predvidenih in opisanih pomenskih razmerij (npr. časovno, načinovno, posledično, pogojno, vzročno, namerno), ki jih slovnica večinoma pripisuje podrednim vezniškim zvezam oz. podrednim odvisnikom. ${ }^{11}$ Odvisniki tretje skupine ne izražajo nobenega izmed predvidenih pomenskih razmerij, kar je bil po vsej verjetnosti tudi eden izmed vzrokov za skoraj popolno izključitev iz slovnične obravnave. Eden izmed vzrokov je zagotovo tudi ta, da se je v slovenski slovnici na odvisnike največkrat gledalo kot na stavčne ustreznike stavčnih členov.

V tej knjigi se pri razporejanju odvisnikov držimo načela njihove stavčnočlenske vloge, obdelani so torej po vrsti odvisniki za osebek, predmet, povedkovo določilo, povedkov prilastek, prislovna določila in za prilastek. (Slovenska slovnica 2000: 638)

Razumevanje odvisnikov kot stavčnih členov se je preneslo tudi v osnovne in srednje šole, žal pa se ni nikoli osredotočalo oz. vidneje opozarjalo na odvisnike, ki svojih ustreznikov med predvidenimi stavčnimi členi nimajo. ${ }^{12}$ Vsekakor pa je treba poudariti, da tudi Slovenska slovnica ta problem nakazuje, ga pa ne razreši in mu ne nameni obširnejše analize.

Izvzemalni odvisnik je stavčno prislovno določilo izvzemanja h glavnemu (ali nadrednemu) stavku. Pretvorljiv je v protivno priredje, npr. Prišli so vsi, le da ne tudi prostovoljno. $\rightarrow$ Prišli so vsi, vendar ne prostovoljno. Še zgledi: Kar pojdi, samo da se ne prehladiš. - Tu ne bi hotel živeti, razen ko je pomlad. Ta odvisnik bi bilo bolje imenovati protivni. (ibid.: 643$)^{13}$

\footnotetext{
${ }_{11}$ Npr. Slovenska slovnica 2000: 432444.

12 Problematično je tudi izhajanje iz strukturnega opisa. Smiselneje bi bilo izhajati iz pomena. Na ta način bi se izognili nevključevanju posameznih konstrukcij, ki, strukturno gledano, ne sodijo v nobeno izmed predvidenih kategorij: ne podredno ne priredno.

${ }_{13} \mathrm{Na}$ tem mestu se zastavlja vprašanje smiselnosti uvrstitve po pomenu različnih odvisnikov v isto skupino (izvzemalni odvisniki oz. protivni odvisniki). Ce sta primera Prišli so vsi, le da ne tudi prostovoljno; Kar pojdi, samo da se ne prehladiš brez pomenskih posegov v glavni stavek res pretvorljiva v protivno zvezo (Prišli so vsi, vendar ne prostovoljno; Kar pojdi, vendar se ne prehladi), pa primer Tu ne bi hotel živeti, razen ko je pomlad, zagotovo ni, kar
} 
Podobno je obravnavan tudi odvisnik, ki ga uvaja protivno vezniško sredstvo medtem ko.

Protivna priredja /.../ izražajo: a) Kontrast ali razliko: Ti boš mlinar, jaz pa ti bom nosila hrano. /.../ Pretvorba v podredje: Medtem ko boš ti mlinar, ti bom jaz nosila hrano: to je protivno podredje. (ibid.: 651)

Podobnih opredelitev je v Slovenski slovnici še več, vendar so obrobne in ne predvidevajo nadaljnjih obravnav in posledično sistematičnih rešitev, ki so nujne, če ne zaradi drugega, zaradi poučevanja slovenščine kot prvega in kot tujega jezika.

Če se vrnemo na obravnavanje odvisnikov kot ustreznikov (nestavčnih) stavčnih členov, je razvidna pomanjkljivost, ki je posledica tega, da med (nestavčnimi) stavčnimi členi ni stavčnega člena protivnosti oz. prislovnega določila protivnosti. Prekrivnost nestavčnih prislovnih določil (ibid.: 619-627) s stavčnimi prislovnimi določili (ibid.: 640-645) je namreč skoraj14 popolna (nestavčna prislovna določila so: prislovno določilo kraja, časa, pravega načina, primere, sredstva in orodja, mere, posledice, ozira, vzroka, namena, pogoja in dopustitve; prislovnodoločilni odvisniki pa so prav tako: odvisnik prostora, časa, načina, primere, posledice, sredstva, ozira, vzroka, namena, pogoja in dopustitve). Odmik k popolni prekrivnosti in usmeritev k nujnosti razširitve prislovnodoločilnih odvisnikov je uvedba izvzemalnega odvisnika (ibid.: 643).

Nujnost razširitve in popolnejšega pregleda pomenske in obenem funkcijske vrednosti (nestavčnih in stavčnih) členov v stavku, predvsem pa prislovnih določil, je posredno nakazana, kot je bilo že večkrat omenjeno, v Slovenski

nadalje nakazuje, da bi ga bilo potrebno obravnavati posebej oz. da ne izraža protivnosti, pač pa pravo izvzemalnost. Poleg tega je odvisnik izvzemalnosti nemalokrat možno pretvoriti tudi v nestavčno izvzemalno zvezo oz. je pomen izvzemalnosti lahko izražen tako stavčno kot nestavčno (kot stavčni člen, ki ga Slovenska slovnica (2000: 619627) ne predvideva.

14 Slovenska slovnica (2000: 625) je uvedla tudi (nestavčno) prislovno določilo vršilca glagolskega dejanja. 
slovnici tudi pri navedbi prislovnih določil lastnosti. ${ }^{15}$

Za osvetlitev predhodno napisanega bodo navedeni trije primeri, s katerimi bomo skušali podati tudi eno izmed možnih rešitev obravnave izhodiščno nestavčnočlenskih (protivnih) odvisnikov in njihovih skladenjsko-pomenskih vlog.

- Medtem ko Vasalisa spi, njena punčka postori zahtevana opravila. ${ }^{16}$

- Medtem ko se v razvitem svetu zavestno, čeprav simbolično odrečemo nekaterim jedem, da bi se osredotočili na duhovno misel in jo okrepili, šestina človeštva ali ena milijarda trpi lakoto, pri čemer ji je takšno stanje vsiljeno.

- Po štirih mesecih ima javna zdravstvena blagajna "zgolj" za okoli 13 milijonov evrov primanjkljaja, medtem ko ga je bilo v trimesečju že 24 milijonov in je grozilo povečanje na prek 100 milijonov evrov do konca leta.

V vseh treh primerih je uporabljeno vezniško sredstvo medtem ko, ki izraža časovno pomensko razmerje, le da je to $\mathrm{v}$ drugem, posebej pa še v tretjem primeru zakrito. Prvi primer je grajen iz matičnega stavka in odvisnika, katerega propozicija ni del propozicije matičnega stavka. Med njima je vzpostavljeno podredno skladenjsko razmerje in pravo časovno pomensko razmerje. Drugi in tretji primer sta po konstrukciji popolnoma enaka prvemu, se pravi, da sta prav tako grajena iz matičnega stavka in neobvezno stavčnočlenskega odvisnika, se pa od njega razlikujeta glede na vzpostavljeno pomensko razmerje. Medtem ko je v prvem primeru izraženo časovno, je v drugem in tretjem poudarjeno predvsem protivno razmerje. $\mathrm{V}$ drugem primeru je poleg protivnosti vzpostavljeno tudi časovno pomensko razmerje, ki pa je

\footnotetext{
15 Lastnostna prislovna določila so: (pravega) načina, sredstva, orodja, mere in primere ... (Slovenska slovnica 2000: 622). V navedenem citatu je pomenljivo končno ločilo tropičje, $s$ katerim je nakazano, da je množica prislovnih določil zagotovo širša, vendar je njen prikaz nepopoln.

16 Vsi primeri so vzeti iz korpusa Gigafida.
} 
delno zakrito oz. postavljeno na drugo raven. $\mathrm{V}$ tretjem primeru je časovno razmerje popolnoma zakrito oz. neizraženo. Vzpostavljeno časovno ali/in protivno pomensko razmerje je/sta odvisno/odvisna ne le od vezniškega oz. konektorskega sredstva, pač pa celotne konstrukcije, zato bi v analizo morali vključiti tudi vsa druga leksikalna in slovnična sredstva.

Vsekakor pa lahko, izhajajoč le iz danih treh primerov, zaključimo a) da bi bilo nujno korpusno izluščiti prav vsa vezniška oz. konektorska sredstva, b) natančno analizirati vse njihove skladenjske in pomenske vloge, pri čemer bi v analizo morali vključiti konstrukcijski pristop, ${ }^{17}$ in c) pri razvrščanju analiziranih konektorskih sredstev bi morali ločevati med skladenjskim in pomenskim razmerjem, kar nadalje pomeni, da bi morali razširiti oz. dopolniti/izpopolniti shemo pomenskih razmerij in posledično shemo strukturnih vlog odvisnikov. Kot je bilo že omenjeno, bi bilo pri analizi smiselno izhajati iz pomenske vloge, ki je lahko strukturno izražena na različne načine (npr. podredno ali priredno). Tako bi poudarili soodvisnost semantične ravni s skladenjsko, pri čemer bi bila primarno analizirana pomenska, sekundarno pa strukturna oz. oblikovna izraženost preučevanega pomena. Ob vsem tem bi bilo nujno $\mathrm{v}$ analizo vključiti tudi jezikovnostilistični vidik, ki bi nakazoval dvofunkcijskost oz. neke vrste homonimijo (dvojno ali celo trojno pomensko in ilokucijsko vrednost) iste strukture. ${ }^{18}$

Ločevanje ${ }^{19}$ skladenjskega in pomenskega razmerja pomeni, da bi se izognili

\footnotetext{
${ }_{17}$ Konstrukcijski pristop pri analizi kateregakoli jezikovnega elementa (na katerikoli jezikovni ravni) vedno vključuje tako pomen kot obliko oz. strukturo. Izhodišče analize predstavlja funkcija, ki jo določen jezikovni element (npr. določena beseda, besedna zveza, stavek itd.) opravlja. Konstrukcijsko metodo oz. konstrukcijsko slovnico je med drugimi natančno opredelil (in zagovarjal) W. Croft v delu Radical construction grammar (2009). Konstrukcije so po njegovem osnovne, temeljne enote vsakega skladenjskega preučevanja in zaobjemajo tako obliko/strukturo kot pomen (2009: str. 14-62).

18 Zveza stavkov Medtem ko Janez spi, France dela lahko izraža zgolj časovno razmerje (istočasnost dveh dejanj), lahko pa zaradi drugačnih kontekstualnih danosti poudarja protivnost, v katero je sicer vključena tudi časovnost, le da je ta delno ali popolno zakrita (Ata dela, mama pa spi.).

19 Ločevanje je na tem mestu izpostavljeno le zaradi nujnosti preseganja tradicionalnega ločevanja med prirednimi vezniškimi sredstvi, ki so jim "predpisana « točno določena
} 
tradicionalnemu ločevanju med prirednimi vezniškimi sredstvi, za katera so tipična točno določena pomenska razmerja (npr. vezalno, ločno, protivno itd.), in podrednimi vezniškimi sredstvi, za katera so značilna druga pomenska razmerja kot pri podrednih vezniških sredstvih (npr. načinovno, posledično, vzročno itd.). ${ }^{20}$ Ločevanje med skladenjskimi in pomenskimi razmerji je izhodiščno seveda nujno, vendar s temeljnima poudarkoma, da lahko isto konektorsko sredstvo izraža različna pomenska razmerja in da lahko isto pomensko razmerje izražajo različna konektorska sredstva (npr. tako podredna kot priredna). To nadalje pomeni, da bi bilo, izhajajoč iz korpusne analize, nujno razširiti oz. dopolniti obravnavo skladenjskih in pomenskih vlog (stavčnih in nestavčnih) obveznih in neobveznih stavčnih členov in družljivih oz. priredno povezanih stavčnih konstrukcij.

\section{4 ČLENKOVNI ODVISNIKI IN PSEVDOHIPOTAKSA}

Členkovni stavki so stavki, ki opravljajo vlogo modifikacije in so blizu ali enaki členkom. S pred ali za njimi stoječimi stavčnimi strukturami vstopajo v priredna ali podredna skladenjska razmerja, vendar le na formalno skladenjski ravni, na pomenski ravni ostaja to razmerje neizpolnjeno.

- $\quad$ Če kdaj, potem tačas koristi »možganska nevihta« z neobremenjenim tretjim. Če kdo, potem Perry: z izkušeno, matematično glavo /.../. ${ }^{21}$

- Sicer pa, če kaj vem, upokojitev Mance Košir pomeni samo to, da bo počenjala mnoge stvari.

- Znanost pa ne more zanikat boga, če še ne veš.

pomenska razmerja, in podrednimi vezniškimi sredstvi, za katera naj bi bila značilna druga pomenska razmerja kot pri podrednih vezniških sredstvih. Tradicionalno ločevanje kot izhodišče postavlja strukturo (podredje, priredje) oz. vezniško sredstvo, in ne pomen. Kot smo že poudarili, bi moral biti kot izhodišče analize postavljen pomen, nadaljnji korak analize pa bi bila preučitev oblikovne/strukturne izpeljave analiziranega pomena.

${ }^{20}$ V Slovenski slovnici lahko npr. preberemo:

Priredni veznik se načeloma ne rabi tudi v podredni zvezi, podredni pa načeloma ne tudi v priredni. (Slovenska slovnica 2000: 432)

${ }^{21}$ Vsi primeri so vzeti iz korpusa Gigafida. 
- $\quad$ Z nobeno kretnjo ali grimaso ni pokazal ne veselja ne jeze, kaj šele da bi preklinjal.

- Od kod veš? se je začudil Bolton. Res si as, če ti rečem.

- Preden greš na izpit, glej, da vse še enkrat ponoviš.

Osredotočili se bomo na prvi primer, in sicer na razmerje med podčrtanima stavkoma če kdaj in če kdo ter matičnima stavkoma, na katera se nanašata. Med njimi namreč ni vzpostavljeno pogojno ali časovno razmerje, tudi protivno ali dopustno ne. Pomenska interpretacija kaže na to, da je vloga stavka če kdaj blizu členkovni vlogi oz. vlogi modifikacije izražanja podkrepitve. Njena osnovna vloga je torej krepitev gotovostne naklonskosti stavka, na katerega se nanaša (če kdaj $\rightarrow$ zagotovo). Stavek če kdaj je ekspresivna stavčna struktura oz. psevdohipotaktična struktura, ki vstopa $\mathrm{v}$ podredno razmerje z za njo stoječim stavkom le na formalni ravni, na pomenski ravni pa je to razmerje prazno, saj opravlja (le) vlogo modifikacijskega sredstva oz. členkovnega stavka. Členkovni stavek kot tak ni del propozicije matičnega stavka, prav tako ne opravlja stavčnočlenske vloge, je pa vsekakor del smiselno-sporočanjske ravni povedi, katere gotovostno naklonskost krepi. Podobno velja tudi za drugi, tretji in predzadnji primer. Nekoliko poseben je četrti primer, saj se razlikuje od preostalih. Če so členkovni stavki v preostalih primerih kot celota modifikatorji (to pomeni, da vsa leksikalna in slovnična sredstva, ki gradijo stavek, skupno opravljajo vlogo modifikacije) in zato pravi členkovni stavki, v četrtem primeru ( $Z$ nobeno kretnjo ali grimaso ni pokazal ne veselja ne jeze, kaj šele da bi preklinjal.) vlogo modifikatorja ne opravlja stavek kot celota, pač pa le določena leksikalna in slovnična sredstva, ki ga gradijo. Tu namreč vlogo izražanja modifikacije opravljajo (le) členkovna zveza kaj šele, veznik oz. uvajalec odvisnika $d a$, struktura stavka (odvisnik) z izraženim pogojnim glagolskim naklonom. Napisano lahko prikažemo s shemo: 
(par.) ${ }^{22}$ kaj šele - (jun.) da - (hipot.) struktura stavka - VF (kond.) $\rightarrow$ krepitev zanikanja

Tabela 1: Konstrukcijski prikaz sooblikovanja vloge krepitve zanikanja

V obravnavanem primeru torej ni pravega členkovnega stavka, ${ }^{23}$ saj vlogo modifikacije, kot je bilo že omenjeno, opravljajo le določena leksikalna in slovnična sredstva. Kljub temu pa so si vsi predhodno navedeni primeri podobni, saj je pri vseh vzpostavljeno psevdohipotaktično razmerje.

Za konec se bomo na kratko osredotočili še na zadnji primer (Preden greš na izpit, glej, da vse še enkrat ponoviš.) V podčrtanem stavku vlogo modifikatorja skupaj opravljajo tako leksikalna kot slovnična sredstva, in sicer členek glej, veznik oz. uvajalec odvisnika $d a$ in povedni glagolski naklon. Njihovo modifikacijsko vrednost (podkrepitev trditve oz. izražanje nujnosti, da vršilec izvede dejanje) bi lahko izrazili/prikazali tudi s pomočjo drugih modalnih izrazov, npr. glagolom morati in členkom nujno/obvezno.

(par.) glej - (jun.) da - (hipot.) struktura stavka - VF (ind. prez ali fut.) ${ }^{24} \rightarrow$ morati (ind. prez ali fut.) - (par.) nujno/obvezno

Tabela 2: Konstrukcijski prikaz sooblikovanja modifikacijske vloge

Tudi tu je obravnavani stavek psevdohipotaktičen, saj je v resnici nadreden stavku (opravlja vlogo glavnega stavka), za katerim stoji: »Preden greš na izpit,

\footnotetext{
22 Par. = členek; jun. = vezniško sredstvo; hipot. $=$ hipotaksa; kond. $=$ pogojni naklon.

23 Obravnavani primer smo $\mathrm{v}$ skupino členkovnih stavkov uvrstili zaradi izraženega psevdohipotaktičnega razmerja, čeprav bi bilo po vsej verjetnosti bolj smiselno, da bi ga uvrstili v skupino izhodiščno nestavčnočlenskih odvisnikov (gl. 2. poglavje pričujočega prispevka: skupina c med odvisniki), saj na pomenski ravni izraža stopnjevalno razmerje, ki ga Slovenska slovnica (npr. Toporišič 2000: 432433) pripisuje le prirednemu skladenjskemu razmerju. Uvrstili bi ga torej lahko med stopnjevalne odvisnike, ki jih, kot že napisano, Slovenska slovnica (2000: 638646) ne predvideva.

24 Ind. = povedni naklon; prez. $=$ sedanjik; fut. $=$ prihodnjik.
} 
moraš vse še enkrat ponoviti // glej, da vse še enkrat ponoviš. « 25

\section{SKLEP IN NALOGE ZA NAPREJ}

Po kratkem pregledu nekaterih najpogostejših oblik odvisnikov lahko kot sklep ponovno zapišemo, da bi bilo nujno korpusno izluščiti vse pojavnice odvisniških oblik in podati njihove skladenjsko-pomenske in pragmatičnosporočanjske vloge. Nujno bi bilo prav tako korpusno pregledati vsa vezniška oz. konektorska sredstva in analizirati njihove skladenjske, pomenske in širše besedilne vloge, pri čemer pa se skladenjskih razmerij ne bi smelo zamenjevati s pomenskimi oz. se določenega pomenskega razmerja ne bi smelo pripisovati izključno določenemu skladenjskemu razmerju, saj bi se lahko le na ta način izognili pomanjkljivi obravnavi odvisnikov in konektorskih sredstev oz. hotenemu ali nehotenemu prezrtju določenih odvisniških konstrukcij in z njimi povezanimi konektorskimi sredstvi. Temeljita analiza vseh oblik odvisnikov in vseh konektorskih sredstev bi nadalje lahko vodila do vzpostavitve novih teoretičnih dognanj.

Vzporedno z analizo večinoma pisnega jezika bi morali vse predhodno napisano preveriti tudi v govornih korpusih. Raven izražanja podrednih medstavčnih skladenjskih razmerij v govorjenem jeziku je zelo slabo raziskana, kar je velika pomanjkljivost, saj ravno poznavanje zakonitosti govorjenega jezika lahko olajša ali pojasni marsikatero težavo, ki se pojavlja v pisnem jeziku. Poleg tega so časovni, vzročni in načinovni odvisniki, katerih propozicije niso del

\footnotetext{
25 Pri uvrstitvi primera Preden greš na izpit, glej, da vse še enkrat ponoviš med členkovne stavke se zastavlja kar nekaj vprašanj, ki deloma nakazujejo, da bi ga bilo morda smiselneje obravnavati kot zvezo glavnega stavka s časovnim in predmetnim odvisnikom. Prvo vprašanje je vezano na opredelitev same besede glej oz. zveze glej $d a$. V pričujočem prispevku jo razumemo kot frazeologizirano členkovno zvezo s pozivno funkcijo (gl. npr. še SSKJ 2, kjer je beseda glej opredeljena kot medmet), čeprav je glej primarno glagolska beseda. Če bi besedo glej opredelili izključno kot glagol (gledati $\rightarrow$ glej, glejta, glejte itd.), se s tem odpira drugo vprašanje oz. pomislek o upravičenosti uvrstitve obravnavanega primera med členkovne stavke. Zvezo bi namreč lahko, kot je bilo uvodoma napisano, opredelili tudi kot zvezo glavnega stavka (glej) z družljivim časovnim odvisnikom (preden greš na izpit) in obveznim predmetnim odvisnikom (da vse še enkrat ponoviš).
} 
propozicije matičnega stavka, tipični predvsem za pisni jezik, v govorjenem jeziku so ta razmerja izražena največkrat s prirednimi skladenjskimi sredstvi. ${ }^{26}$ V izbranem korpusu oz. zbirki ${ }^{27}$ spontano govorjenih narativnih besedil 34 govorcev, ${ }^{28}$ ki je bila oblikovana prav zaradi analize skladenjskih značilnosti spontano govorjenega jezika, se potrjuje, da je med najpogosteje rabljenimi vezniškimi sredstvi v spontano govorjenem jeziku prav veznik in, ki povezuje tudi propozicije oz. stavke, ki so med seboj v posledičnem, vzročnem, načinovnem ali časovnem pomenskem razmerju. Vzporedna analiza izražanja medstavčnih skladenjskih in pomenskih razmerij je torej nujna ne le zaradi kontrastive in same jezikoslovne stroke, pač pa predvsem zaradi boljših izhodišč pri poučevanju slovenščine kot prvega in tujega/drugega jezika.

\section{LITERATURA}

Ahačič, K. (2017): Slovnica na kvadrat. Slovenska slovnica za srednjo šolo. Ljubljana: Rokus Klett.

Cazinkić, R. (2001): Kategorizacija in razvrstitev oziralnikov ki in kateri. Slavistična revija 49/1-2. 55-73.

Cazinkić, R. (2004): Pojmovanje odvisnika in razmerja med nadrednim in odvisnim stavkom. Jezikoslovni zapiski 10/1. 43-58.

Croft, W. (2009): Radical Construction Grammar: Syntactic Theory in

${ }_{26}$ Večkrat je bilo že potrjeno, da se je podredno izražanje časovnih, vzročnostnih in načinovnih razmerij uveljavilo s pisnim jezikom, sicer pa so ista razmerja v govorih navadno oz. praviloma priredno izražena. (Grepl 2011: 170 po Žele 2016: 88).

[U] govorenom jeziku se općenito ljudi jednostavnije izražavaju i koriste kraće rečenične konstrukcije pa se zato mnoge rečenice koje bi se u pisanom jeziku ostvarile kao nerestriktivne relativne rečenice ostvaraju u govorenom jeziku kao nezavisne rečenice /.../. (Kordić 1995: 6263)

${ }^{27}$ Skupni obseg posnetih besedil je 148.427 znakov brez presledka v zapisani obliki besedila. Besedila so v zapisani obliki objavljena v: Smolej, Mojca, 2012: Besedilne vrste $v$ spontanem govoru.

${ }_{28}$ Vsi govorci so zaradi enotnosti in usklajenosti jezikovne analize na ravni pokrajinske oz. zvrstne opredelitve jezika iz Ljubljane ali njene okolice. Govorci, ki so tvorili vsak le po eno besedilo, se razlikujejo glede na spol (12 moških, 22 žensk), starost (najmlajši govorec je bil star 21 let, najstarejši pa 72) in vrsto izobrazbe. 
Typological Perspective. Oxford: Oxford University Press.

Gabrovšek, D. (2016): Psevdohipotaksa: primer vezniških besed medtem ko, namesto da, kar. Diplomsko delo, Filozofska fakulteta, Univerza v Ljubljani.

Gelb, J. (1969): Podredje v vlogi priredja. Jezik in slovstvo 5/14. 136-139.

Gigafida. Dostopno prek: http://www.gigafida.net (22. december 2017).

Goldberg, A. E. (1995): A Construction Grammar Approach to Argument Structure. Chicago: The University of Chicago Press.

Kordić, S. (1995): Relativna rečenica. Zagreb: Hrvatsko filološko društvo, Matica hrvatska.

Kos, M. (2016): Skladenjske konstrukcije med podredjem in priredjem. Diplomsko delo, Filozofska fakulteta, Univerza v Ljubljani.

Pogorelec, B. (1963): Veznik v slovenščini. Doktorska disertacija, Filozofska fakulteta, Univerza v Ljubljani.

Slovar slovenskega knjižnega jezika² (2014). Ljubljana: ZRC SAZU. Dostopno prek: https://fran.si/ (7. november 2018).

Sovre, A. (1965): Nepravi relativniki. Jezikovni pogovori. Ljubljana: Cankarjeva založba. 125-131.

Smolej, M. (2011): Skladnja slovenskega knjižnega jezika. Izbrana poglavja z vajami. Ljubljana: Študentska založba.

Smolej, M. (2012): Besedilne vrste v spontanem govoru. Ljubljana: Znanstvena založba Filozofske fakultete.

Smolej, M. (2015): Particle clauses. Slovenski jezik - Slovene Linguistic Studies 10. 127-137.

Toporišič, J. (1982): Nova slovenska skladnja. Ljubljana: DZS. 
Toporišič, J. (2000): Slovenska slovnica. Maribor: Obzorja.

Bajec, A., R. Kolarič in M. Rupel. (1956): Slovenska slovnica. Ljubljana: DZS.

Žele, A. (2016a): Tipologija odvisnikov v slovenščini: merila. E. Kržišnik (ur.): Toporišičeva obdobja. Ljubljana: Znanstvena založba Filozofske fakultete. 299-306.

Žele, A. (2016b): Odvisniki v slovenščini: vsebinski odvisniki in nepravi prislovnodoločilni odvisniki. Slavistična revija 64/2. 81-94.

Žele, A. (2017): Razmerje osebek proti osebkov odvisnik v slovenskih povedih. Slavistična revija 65/1. 81-97. 


\section{SYNTAX CONSTRUCTIONS BETWEEN HYPOTAXIS AND PARATAXIS}

Sentences in the form of subordinate clauses perform numerous syntactic and semantic roles. The number of different forms and roles of subordinate clauses is large but unfortunately not yet fully described. Some subordinate clauses are almost completely ignored in the Slovenian linguistics. On the basis of primary functions, subordinate clauses are divided into four basic groups: a) subordinate clauses that are part of the main clause; b) subordinate clauses that are not part of the semantic knot of the main clause; c) subordinate clauses that are subordinate only on the structural level and are originally not part of the speech; d) subordinate clauses that are subordinate only on the structural level, but perform the role of modifiers of the main clause on the semantic level and are therefore called particle clauses. In this article, we then focus more precisely on subordinate clauses of the third group that do not express any of the foreseen semantic relations; and that is probably one of the reasons why they are almost completely excluded from grammatical treatment. Surely, one of the reasons is also that in the Slovenian grammar the subordinate clauses are often looked at as the clause equivalents of sentence clauses. The understanding of subordinate clauses as sentence clauses was transferred also to primary and high schools but sadly, there has never been a focus or strong emphasis on those subordinate clauses that do not have their own equivalents among expected sentence clauses. Similar are particle subordinate clauses which form coordinate or subordinate syntactic relationships with the pre or after positioned sentence structures only on the formal syntactic level and not on the semantic level. The above written is also one of the main reasons why the Slovenian grammar has not yet included them into its study. The analysis shows that it would be necessary to find all occurrences of subordinate forms in the corpus and define their new syntacticsemantic and pragmatic-communication roles. It would also be necessary to look at all connector means in the corpus and analyse their syntactic, semantic, and broader text roles, and by so doing the syntactic relations should not be confused with semantic ones. A thorough analysis of all forms of subordinate clauses and all connector means could further lead to new theoretical findings. Everything 
written so far should, along with the analysis of the majority of the written language, also be verified in spoken corpora.

Keywords: subordinate clauses, pseudohypotaxis, oppositional/contrastive subordinate clauses, particle clauses

To delo je ponujeno pod licenco Creative Commons: Priznanje avtorstvaDeljenje pod enakimi pogoji 4.o Mednarodna.

This work is licensed under the Creative Commons Attribution-ShareAlike 4.0 International.

https://creativecommons.org/licenses/by-sa/4.o/

(c) (1) () 